\title{
HUBUNGAN ANTARA ORIENTASI NILAI (VALUE ORIENTATION) DENGAN PARADIGMA LINGKUNGAN BARU NEW ENVIRONMENTAL PARADIGM) SISWA
}

\author{
Amalia Fitri Dwi Widyati', I Made Putrawan², Mieke Miarsyah ${ }^{3}$ \\ ${ }^{1}$ Student of Biology Education Departement of State University of Jakarta \\ ${ }^{2}$ Environmental Education Departement of State University of Jakarta \\ ${ }^{3}$ Biology Education Departement of State University of Jakarta \\ Email : lia10fitri@gmail.com, putrawan.imade@yahoo.com, mmiarsyah@unj.ac.id
}

\begin{abstract}
New Environmental Paradigm merupakan hasil interaksi dari berbagai faktor seperti personality, environmental concern dan salah satunya adalah value orientation. Penelitian ini bertujuan untuk mengetahui hubungan antara value orientation dengan new environmental paradigm pada siswa SMA di Jakarta. Penelitian ini dilaksanakan di SMAN 22 Jakarta pada Semester I Tahun Ajaran 2019/2020. Metode yang digunakan adalah metode survei dengan studi korelasional. Data dikumpulkan menggunakan instrumen value orientation dan new environmental paradigm. Analisis data dilakukan dengan uji regresi linear sederhana untuk mengukur besarnya hubungan digunakan Pearson Product Moment. Hasil Penelitian menunjukkan terdapat hubungan yang positif dan signifikan antara value orientation dengan new environmental paradigm. Bahwa individu yang peduli akan kesejahteraan untuk dirinya sendiri, orang lain dan lingkungan akan memiliki sifat positif untuk memandang lingkungan baru. Oleh karena itu value orientation memiliki peranan dalam paradigma lingkungan baru siswa.
\end{abstract}

Keywords : New Environmental Paradigm, Value Orientation, Siswa 


\section{PENDAHULUAN}

Semakin majunya perkembangan zaman, semakin banyak terjadinya masalah lingkungan yang disebabkan oleh perilaku manusia. Dikarenakan manusia adalah mahluk hidup yang memiliki rasa ego yang lebih tinggi daripada mahluk hidup lain, sehingga manusia merasa superior di bumi dari mahluk hidup yang lain. Perilaku manusia yang merasa superior di bumi ini menyebabkan alam mengalami penipisan ozon, pemanasan global, penggundulan hutan, dan hilangnya spesies langka yang merupakan masalah lingkungan hidup akibat manusia. Oleh karena itu banyak terjadinya bencana alam dimuka bumi ini. Individu melihat lingkungan dan berpendapat bahwa manusia tidak memiliki hubungan dengan alam, manusia tidak ada sangkut-pautnya dengan organisme lain, manusia memiliki pemikiran yang lebih maju dibandingkan organisme lainnya sehingga berhak untuk menguasai sumber daya alam seutuhnya.( Denzin \& Linclon, 2009).

New Environmental Pardigm merupakan cara pandang baru yang mencerminkan adanya kepedulian yang lebih baik terhadap lingkungan. Pada hakikatnya, paradigma menurut Spellerberg adalah sebuah gambaran/ pandangan dasar suatu subjek ilmu.( Spellerberg, 2012) New Environmental Paradigma (NEP) bisa disebut sebagai paradigma ekologi baru.( Putrawan,2015) Sebagaimana paradigma lingkungan baru karena adanya peningkatan pandangan manusia terhadap lingkungan tempat manusia tinggal perubahan paradigma dari anti ekologis sampai pro ekologis.(Putrawan,2019).

Manusia memiliki tiga value orientation dalam hidupnya yaitu value orientation sikap egoistic, altruistic, dan biospheric.(Dunlap,2000) Manusia dengan value orientation egoistic akan mempertimbangkan biaya dan manfaat terutama jika manfaat yang dirasakan melebihi biaya yang dikeluarkan oleh manusia maka orang tersebut akan memiliki niat ramah lingkungan dan sebaliknya.(Putrawan, 2019) Orang-orang dengan value orientation sosial altruistic akan mendasarkan keputusannya untuk berperilaku proenvironmental yang tidak mementingkan biaya dan manfaat untuk dirinya sendiri. Akhirnya, orang-orang dengan value orientation biospheric terutama akan mendasarkan keputusannya untuk bertindak proenvironmentally atau tanpa melihat pada biaya yang dirasakan dan lebih melihat manfaat bagi ekosistem dan biosfer secara keseluruhan. 


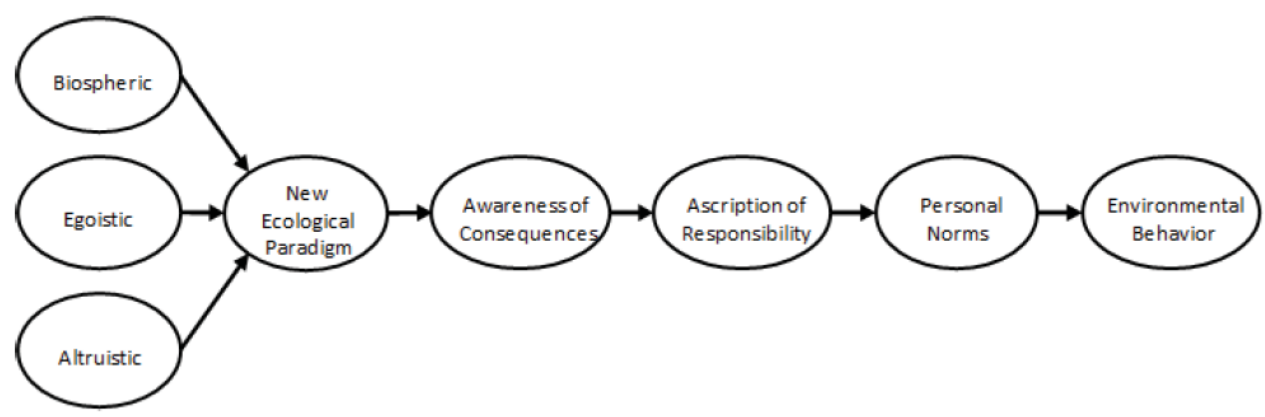

Terdapat conceptual of research model hypothesis menurut $\mathrm{Yu} \& \mathrm{Yu}$ yang dimodifikasi dari model VBN oleh Stern dimana value orientation menjadi sustainability value memiliki hubungan dengan new environmental paradigm.(Stern, 2000) New environmental paradigm adalah suatu cara pandang seseorang dalam mengelola alam bukan hanya untuk mencapai terget ekonomi yang diinginkan tetapi tetap menjaga lingkungan. New environmental paradigm ini dapat dilihat ketika siswa mulai menggunakan teknologi yang ramah lingkungan, melakukan perlindungan terhadap lingkungan dari kepentingan ekonomi.

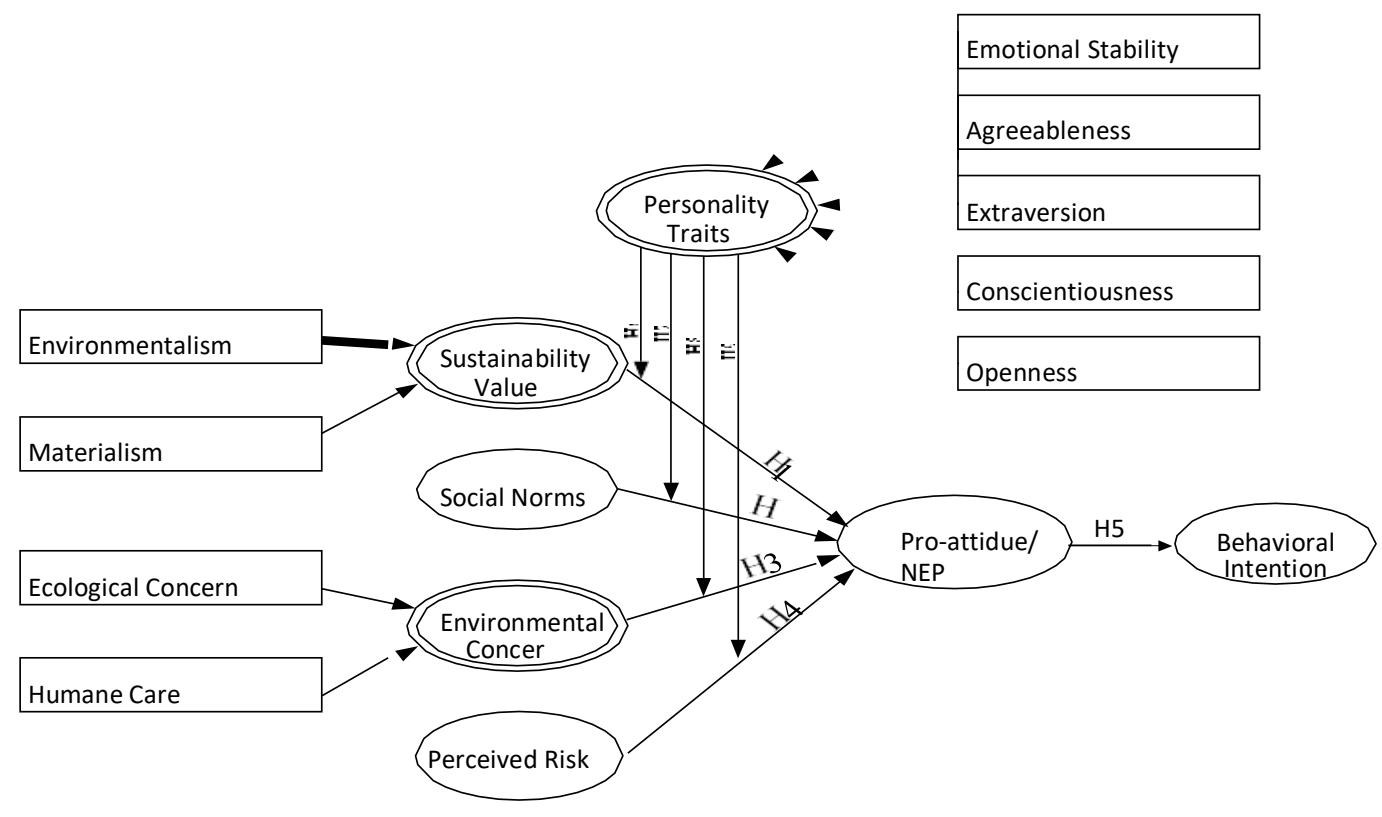

Gambar 2. Gambar 1. VBN model for environmental behavior

New environmental paradigm adalah suatu cara pandang seseorang dalam mengelola alam bukan hanya untuk mencapai terget ekonomi yang diinginkan tetapi tetap menjaga 
lingkungan. New environmental paradigm ini dapat dilihat ketika siswa mulai menggunakan teknologi yang ramah lingkungan, melakukan perlindungan terhadap lingkungan dari kepentingan ekonomi.

Menurut Dunlap, et al, paradigma lingkungan baru (new environmental paradigm) terdiri atas 5 dimensi yaitu : 1) Realitas tentang adanya batas pertumbuhan (Limits to growth), 2) Anti-antroposentrisme (Anti-antropocentricsm), 3) Kerapuhan pada keseimbangan alam (The fragility of natures balance), 4) Penolakan terhadap exemtionalism (Rejection of examptionalism), 5) Kemungkinan adanya krisis ekologi (the possibility of an ecocrisis). (Dunlap, et. al., 2002).

Indikator yang digunakan yaitu untuk biospheric dilihat dari kewajiban manusia melindungi SDA (preventing pollution), hidup harmoni berdampingan dengan alam (respecting the earth), manusia hidup sebagian dari alam (unity with nature), pelestarian lingkungan (protecting the earth). Sedangkan, indikator yang digunakan untuk altruistic adalah persamaan kedudukan, perdamaian, keadilan sosial, bantuan informal, untuk dimensi egoistic adalah sosial power, mempengaruhi manusia, sebagai penguasaan terhadap sumber daya alam, mendapatkan keuntungan.

Rumusan masalah dalam penelitian ini adalah "apakah terdapat hubungan antara value orientation dengan new environmental paradigm siswa ?". Tujuan dari penelitian ini adalah untuk mengetahui hubungan antara value orientation dengan new environmental paradigm siswa.

\section{METODOLOGI PENELITIAN}

Metode yang digunakan pada penelitian ini adalah metode deskriptif dengan studi korelasional. Penelitian ini mempunyai dua variabel, yaitu X (Value Orientation) sebagai variabel bebas dan Y (New Environmental Paradigm) merupakan variabel terikat. Model konstelasi pada penelitian yang digunakan dalam penelitian ini adalah : 


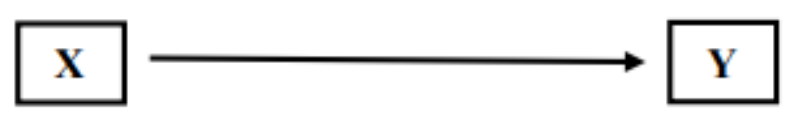

Gambar 2. Model Konstelasi Hubungan antara X dan Y

Keterangan :

$\mathrm{X}$ : Value Orientation

$\mathrm{Y}$ : New Environmental Paradigm

Dalam penelitian ini pemilihan sampel dan populasi dilakukan dengan menggunakan teknik pemilihan sampel bertingkat (multi stage random sampling) dengan tahapan sebagai berikut : Pertama, pemilihan populasi penelitian yang akan diteliti adalah seluruh siswa SMA Negeri kelas XI MIPA di Provinsi DKI Jakarta. Kedua dari seluruh siswa SMA Negeri kelas XI MIPA di Jakarta, dipilih SMA Negeri di Jakarta Timur dengan teknik purposive sampling. Ketiga, dengan menggunakan teknik cluster random sampling dari 10 kecamatan di wilayah Jakarta timur terpilihlah satu kecamatan Matraman di Jakarta Timur. Keempat, pemilihan sekolah dengan menggunakan teknik cluster random sampling dari seluruh SMA di kecamatan Matraman di wilayah Jakarta Timur terpilihlah SMAN 22 Jakarta sebagai tempat penelitian. Kelima, dengan menggunakan teknik cluster random sampling dipilih 3 kelas XI MIPA dari jumlah keseluruhan kelas XI MIPA, dipilih 105 siswa sebagai responden. Keenam, dengan menggunakan teknik simple random sampling diambil secara acak 100 sampel dari 105 responden yang terpilih. Pada penelitian ini, teknik pengumpulan data yang digunakan adalah metode survei dengan instrument berupa opinioner untuk value orientation dan instrumen berupa opinioner untuk mengukur new environmental paradigm.

\section{HASIL DAN PEMBAHASAN}

Hasil pengujian regresi linear sederhana menunjukkan bahwa data value orientasi dengan new environmental paradigm membentuk model regresi yang signifikan dan linear dirumuskan sebagai berikut $\hat{Y}=65,541+0,480 X$. Model persamaan tersebut menunjukkan bahwa hubungan ketiga dimensi value orientation dengan new environmental paradigm 
memiliki hubungan yang positif, bisa dilihat $t_{\text {hitung }}$ lebih besar dari pada $t_{\text {tabel }}$ yaitu 6.50>1.66.

Hal ini menunjukkan apabila value orientation bertambah 1 skor maka akan diikuti oleh kenaikan skor new environmental paradigm siswa (Y) sebesar 0,480 dengan konstanta 65.541.

Dapat dilihat pada tabel 1 sebagai berikut :

Tabel 1. Model Persamaan Regresi Linear Sederhana

\begin{tabular}{|c|c|c|c|c|c|c|c|c|}
\hline \multicolumn{9}{|c|}{$\hat{\mathrm{Y}}=65,541+0,480 \mathrm{X}$} \\
\hline \multirow[t]{2}{*}{ Model } & \multicolumn{2}{|c|}{$\begin{array}{l}\text { Unstandardized } \\
\text { Coefficients }\end{array}$} & \multirow{2}{*}{$\begin{array}{c}\text { Standardized } \\
\text { Coefficients } \\
\text { Beta }\end{array}$} & \multirow[t]{2}{*}{$t_{\text {hitung }}$} & \multirow[t]{2}{*}{$\mathrm{t}_{\text {tabel }}$} & \multicolumn{3}{|c|}{ Correlations } \\
\hline & $\mathrm{B}$ & $\begin{array}{l}\text { Std. } \\
\text { Error }\end{array}$ & & & & $\begin{array}{l}\text { Zero- } \\
\text { order }\end{array}$ & $\begin{array}{c}\text { Partia } \\
1 \\
\end{array}$ & Part \\
\hline (Constant) & 65.541 & 7.859 & & 8.339 & .000 & & & \\
\hline $\begin{array}{l}\text { 1 VALUE } \\
\text { ORIENTATION }\end{array}$ & .480 & .061 & .622 & 6.50 & 1.66 & .622 & .622 & .622 \\
\hline
\end{tabular}

a. Dependent Variable: NEP

Sebelum model regresi tersebut dianalisis lebih lanjut, terlebih dahulu dilakukan uji signifikan dan linieritas model persamaan regresi. Untuk melakukan uji keberartian regresi menggunakan uji ANAVA regresi dari variabel yang diukur yaitu value orientation terhadap new environmental paradigm. Hasil uji regresi signifikansi disajikan dalam tabel 2 Sebagai berikut :

Tabel 2. . Uji Signifikan Persamaan Model Regresi

\begin{tabular}{rlrrrrr}
\hline Model & & \multicolumn{1}{c}{$\begin{array}{l}\text { Sum of } \\
\text { Squares }\end{array}$} & df & \multicolumn{1}{c}{$\begin{array}{c}\text { Mean } \\
\text { Square }\end{array}$} & F hitung & $F_{\text {tabel }}$ \\
\hline \multirow{3}{*}{1} & Regression & 3438.358 & 1 & 3438.358 & 61.848 & 3.9381 \\
& Residual & 5448.152 & 98 & 55.593 & & \\
& Total & 8886.510 & 99 & & & \\
\hline
\end{tabular}

a. Dependent Variable: NEP

b. Predictors: (Constant), VALUE ORIENTATION 
Dari ketiga dimensi setelah melakukan pengujian keberartian model regresi pada $\mathrm{a}=$ 0,05 didapatkan hasil yang menunjukkan bahwa $F_{\text {hitung }}$ lebih besar dari $F_{\text {tabel }}$ yaitu 61.848>3.938 maka tolak H0. Hal ini menunjukkan model regresi sederhana yang didapatkan adalah signifikan. Untuk mengetahui bahwa hasil dari ketiga dimensi value orientation dengan new environmental paradigm linear, dibutuhkan uji linearitas. Hasil yang didapatkan adalah pada $\mathrm{a}=0,05$ value orientation memiliki hubungan yang linear dengan new environmental paradigm. Selanjutnya untuk mengetahui seberapa besar kontribusi value orientation dengan new environmental paradigm perlu mengetahui koefisien determinasi. Berdasarkan hasil perhitungan diperoleh nilai koefisien determinasi dari kedua variabel yaitu 0,387. Koefisien determinasi untuk value orientation terhadap new environmental paradigm tersebut sebesar $38,7 \%$ artinya bahwa value orientation memberikan konstribusi terhadap variabel new environmental paradigm. Dapat dilihat pada tabel 4 berikut ini :

Tabel 3. Tabel Partial biospheric, altruistic, egoistic

\begin{tabular}{lrrr}
\hline Model & \multicolumn{3}{c}{ Correlations } \\
\cline { 2 - 4 } & Zero-order & Partial & Part \\
\hline (Constant) & & & \\
\multicolumn{1}{c}{ Bios } & .579 & $\mathbf{. 1 3 9}$ & .110 \\
Altru & .570 & $\mathbf{. 1 6 8}$ & .134 \\
Egos & .536 & $\mathbf{. 2 0 4}$ & .163 \\
\hline
\end{tabular}

Tabel 4. Koefisien determinasi

\begin{tabular}{|c|c|c|c|c|c|c|c|c|c|}
\hline \multirow{2}{*}{$\begin{array}{l}\text { Mo } \\
\text { del }\end{array}$} & \multirow[t]{2}{*}{$\mathrm{R}$} & \multirow{2}{*}{$\begin{array}{c}\mathrm{R} \\
\text { Squar } \\
\mathrm{e}\end{array}$} & \multirow{2}{*}{$\begin{array}{l}\text { Adjusted } \\
\text { R Square }\end{array}$} & Std. & \multicolumn{5}{|c|}{ Change Statistics } \\
\hline & & & & $\begin{array}{l}\text { Error of } \\
\text { the } \\
\text { Estimate }\end{array}$ & $\begin{array}{c}\text { R Square } \\
\text { Change }\end{array}$ & $\begin{array}{c}\text { F } \\
\text { Chang } \\
\mathrm{e}\end{array}$ & df1 & df 2 & Ftabel \\
\hline 1 & $.622^{\mathrm{a}}$ & .387 & .368 & 7.533 & .387 & 20.203 & 3 & 96 & 3.9381 \\
\hline
\end{tabular}

a. Predictors: (Constant), egoistic, altruistic, biospheric

b. Dependent Variable: new environmental paradigm

Untuk mengetahui kontibusi dari ketiga dimensi value orientation dengan new environmental paradigm. Dibutuhkan mengetahui koefisien partial dari ketiga dimensi. Didapatkan kontribusi terbesar dari ketiga dimensi value orientation adalah egoistic sebesar 
2,04\%, kontribusi terbesar yang kedua adalah dimensi altruistic sebesar 1,68\% dan dimensi yang paling rendah kontribusinya yaitu biospheric sebesar 1,39\%. Berdasarkan hipotesis penelitian setelah dilakukan pengujian hipotesis didapatkan bahwa ketiga dimensi value orientation memiliki hubungan yang positif dengan new environmental paradigm. Hal ini terbukti pada hasil perhitungan model persamaan regresi yang menunjukkan bahwa adanya hubungan yang positif antara ketiga dimensi value orientation dengan new environmental paradigm. Hal ini dikarenakan bahwa individu yang peduli akan kesejahteraan untuk dirinya sendiri, orang lain dan lingkungan akan memiliki sifat positif untuk memandang lingkungan baru. Nilai biospheric, nilai altruistic dan nilai egoistic berkontribusi positif dan signifikan terhadap new environmental paradigm.( Schultz, P. W. 2001)

Nilai koefisien korelasi value orientation sebesar 0,622. Untuk koefisien determinasi dari kedua variabel tersebut didapatkan 0,387 dapat diinterprestasikan bahwa value orientation memiliki kontribusi sebesar $38,7 \%$ terhadap new environmental paradigm. Value orientation memiliki tanggung jawab penuh terhadap new environmental paradigm, bahwa new environmental paradigm ditentukan oleh nilai-nilai orientasi masyarakat yang terdiri dari biospheric, altruistic,egoistic.(Putrawan,2019).

Pada penelitian ini ingin mengetahui hubungan setiap dimensi value orientation dengan new environmental paradigm. Untuk mengetahui hubungan setiap dimensi value orientation dibutuhkan breakdown dari setiap dimensi value orientation. Hasil dari breakdown ketiga dimensi value orientation didapatkan koefisien partial untuk biospheric sebesar 0,139 , untuk altruisric sebesar 0,168 dan terakhir untuk egoistic sebesar 0,204. Hal ini menunjukkan bahwa koefisien terbesar dari ketiga dimensi value orientation adalah dimensi egoistic.

Hubungan dimensi value orientation dengan new environmental paradigm ternyata yang paling berhubungan dalam penelitian ini adalah dimensi egoistic dengan new environmental paradigm. Hal ini menunjukkan bahwa siswa dalam penelitian ini mendapatkan orientasi nilai egoistic yang positif untuk memandang lingkungan yang baru dengan kuat. Hal ini bisa dilihat berdasarkan instrumen yang diberikan kepada siswa, rata-rata jawaban yang diberikan merupakan jawaban yang berasal dari dalam dirinya seperti akan ikut menjaga lingkungan jika dipaksa, menjadikan uang adalah hal terpenting bagi kehidupan. Ini menunjukkan bahwa siswa dalam penelitian ini ingin menciptakan sikap positif terhadap 
lingkungan diikuti dengan orientasi nilai dalam dirinya yaitu egoistic. Sesuai dengan penelitian yang dilakukan oleh (Chua,2016) bahwa sampel penelitian memiliki nilai egoistic yang positif untuk menciptakan sikap lingkungan, sehingga dapat difokuskan nilai egoistic untuk meningkatkan kesejahteraan lingkungan.

Terdapat beberapa alasan dan faktor yang mempengaruhi siswa dalam berpandangan terhadap lingkungan baru. Faktor tersebut adalah karena kemajuan teknologi dan pengaruh lingkungan, pengaruh lingkungan bisa menyebabkan siswa ingin mempunyai standar hidup yang lebih tinggi terhadap lingkungan. Sesuai dengan penelitian (Chung \& Poon,2000) yaitu dominasi tujuan material atau egoistic yang positif adalah keinginan untuk mempunyai standar hidup yang lebih tinggi dapat mengarah pada pandangan nilai tentang alam. Banyak orang percaya bahwa manusia memiliki hak untuk membuatnya dalam setiap penggunaan alam dan sumber daya alam yang memungkinkannya untuk memenuhi kebutuhannya. Teknologi juga menjadikan faktor utama dalam mempengaruhi siswa dalam penelitian ini terutama siswa dalam penelitian ini adalah siswa generasi z. Ciri-ciri generasi z adalah orang yang dilahirkan dengan teknologi saat ini, dan termasuk digital center dan yang terakhir teknologi adalah identitas mereka.(Shilpa,Arora,\&Bhuvanesh. 2009)

Tidak menutup kemungkinan orang yang memiliki orientasi nilai egoistic yang tinggi tidak ingin mendapatkan lingkungan yang lebih baik. Orang dengan nilai eogistic yang tinggi memiliki pandangan lingkungan baru dengan didasari kepentingan untuk diri sendiri terhadap lingkungan. Sesuai dengan penelitian (Chang,2015) yang mendapatkan korelasi yang positif antara kekuasaan dengan paradigma ekologi baru. Hal ini menunjukkan bahwa orang yang memiliki nilai egoistic tidak selalu dikaitkan dengan menurunnya penerimaan paradigma lingkungan baru, karena individu dengan nilai egoistic mungkin ingin melindungi lingkungan karena alasan yang berasal dari kepentingan pribadi.

Dalam penelitian ini dimensi kedua yang berkontribusi tinggi adalah altruistic. Siswa memiliki orientasi nilai altruistic yang tinggi dalam memandang lingkungan yang baru dikarenakan beberapa faktor. Faktor yang paling mendukung adalah dari dalam dirinya karena memandang lingkungan lebih berarti dari diriya, faktor yang kedua adalah karena keadaan alam yang sudah semakin memburuk sehingga muncul rasa prihatin dari dalam dirinya terhadap lingkungan. 
Dimensi yang ketiga yang berkontribusi terhadap new environmental paradigm adalah biospheric. Pada penelitian ini biospheric mendapatkan tingkatan ke tiga dikarenakan siswa dalam penelitian ini memandang alam bukan hanya ingin melindungi biosfer melainkan masih didominasi oleh rasa prihatin dan egoisme yang tinggi. Terdapat faktor yang menyebabkan biospheric dalam penelitian ini menempati urutan ketiga, yang pertama faktor lingkungan siswa yang tidak mendukung untuk memandang paradigma lingkungan baru dengan orientasi nilai biospheric melainkan lebih realistis dengan keadaan lingkungan siswa. Faktor yang kedua adalah kondisi keuangan keluarga siswa. Faktor yang ketiga adalah teknologi, dan faktor yang ke empat adalah tidak memiliki empati terhadap alam.

Pada tahun 2015 Genying Chang melakukan penelitian yang berjudul Materialist Value Orientation As Correlates Of The New Ecological Paradigm Among University Students In China. Hasil dari penelitian ini adalah Value orientation menunjukkan hubungan korelasi yang kuat dengan paradigm lingkungan baru melalui mediasi prioritas ekonomi terhadap lingkungan. (Chang, 2015). Pada tahun 2016 Chua melakukan penelitian yang berjudul The Mediating Role of New Ecological Paradigm between Value Orientations and Pro-Environmental Personal Norm in the Agricultural Context. Hasil dari penelitian ini adalah egoistic memiliki hubungan yang positif dengan new environmental paradigm. (Chua, 2016) Kedua penelitian tersebut sesuai dengan temuan dalam penelitian ini dimana value orientation khususnya egoistic memiliki hubungan yang positif dengan new environmental paradigm.

Dari kedua penelitian ini membuktikan bahwa seseorang memandang paradigma lingkungan baru dengan didasari oleh ketiga dimensi value orientation yang saling berhubungan terhadap new environmental paradigm. Ketika seseorang memiliki salah satu value orientation dalam dirinya maka akan mempengaruhi cara seseorang untuk memandang paradigma lingkungan baru. Sesuai dengan model hipotesis Tai-Yi Yu dan Tai-Kuei Yu bahwa setiap orang mempunyai orientasi nilai yang berbeda dalam memandang suatu paradigma lingkungan baru dalam mewujudkan perilaku berlingkungan, memang perlu adanya new environmental paradigm terlebih dahulu.(Yi\&Yu,2017) 
Siswa dengan orientasi nilai egoisme yang tinggi tidak boleh di diskriminasi untuk caranya memandang paradigma lingkungan yang baru. Belum tentu siswa yang memiliki egoistic yang positif tidak memiliki new environmental paradigm yang kuat, justru siswa tersebut akan memiliki new environmental paradigm yang kuat jika kondisi lingkungan sudah mengancam dirinya. Sama seperti siswa yang memiliki nilai biospheric dan altruistic, siswa yang memiliki nilai egoistic yang tinggi juga berperan dalam melihat new environmental paradigm di lingkungan siswa untuk ikut serta menjaga lingkungan.

\section{KESIMPULAN}

Setelah melakukan penelitian, dalam penelitian ini didapatkan adanya hubungan positif antara ketiga dimensi value orientation dengan new environmental paradigm pada siswa. Kontribusi teritinggi dari ketiga dimensi value orientation adalah egoistic terhadap new environmental paradigm. Sehingga dapat disimpulkan bahwa terdapat hubungan positif antara value orientation terhadap new environmental paradigm, maka makin egoistic maka makin kuat new environmental paradigm. Value orientation dapat didukung oleh beberapa faktor yaitu ekonomi, keadaan lingkungan, dan teknologi.

\section{REFERENSI}

Denzin \& Lincoln, Hanbook of Qualitative Research, di terjemahkan oleh Dariyatno dkk, (Yogyakarta: Pustaka Pelajar, 2009)

Chuang, S. S. , \& Poon, C. S . ( 2000 ) "A comparison of waste-reduction practices and the new environmental paradigm in four Southern Chinese areas ". Environmental Management, 26 ( 2 ), 195 - 206.

Genying Chang.2015 "Materialist Value Orientation As Correlates Of The New Ecological Paradigm Among University Students In China”, Psychological Reports: Sociocultural Issues in Psychology,116 (02), 597-612. 
I Made Putrawan.(2015)“Measuring New Environmental Paradigm Based on Student's Knowledge About Ecosystem and Locus of Control”, Eurasia Journal of Mathematics, Science, \& Technology Education, 11(2), P. 326

I Made Putrawan \& Lisa Ningtyas,(2019) "The Role of Environmental Leadership and Personality on VBN Model",Indian Journal of Public Health Research \& Develpoment, Vol. 10 No. 09

I Made Putrawan \& Rizki Ananda.(2019) “Construct Validity of Biological Students' New Environmental Paradigm (NEP) Dimensions based on Gender”, Jour of Adv Research in Dynamical \& Control Systems, Vol. 11(09)

I Made Putrawan \& Rizki Ananda.(2019) “A Comparative Analysis of New Ecological Paradigm (NEP), Ecosystem Knowledge, and Students' Self-Control Based on Gender”, International Journal of Innovative Technology and Exploring Engineering, Vol. 8

I Made Putrawan \& Rizki Ananda.(2019) “A Mediated Role Of Students New Environmental Paradigm (NEP) Between Environmental Personality and Pro Eco Behavior”,", Indian Journal of Public Health Research \& Develpoment, Vol. 10(1)

Kean Boon Chua Farzana Quoquab Jihad Mohammad Rohaida Basiruddin , (2016),"The Mediating Role of New Ecological Paradigm between Value Orientations and ProEnvironmental Personal Norm in the Agricultural Context", Asia Pacific Journal of Marketing and Logistics, Vol. 28

Dunlap, V. R., \& dkk. (2000). Measuring Endorsement of the New Ecological Paradigm: A Revised NEP Scale. Journal of Social Issues, 56(3), 425-442. 
Shilpa,Arora,\&Bhuvanesh. (2009). Understanding The Attitude Of Generation Z Towards Workplace. International Journal of Management, Technology And Engineering, Volume 9(1)

Schultz, P. W. (2001). The structure of environmental concern: concern for self, other people, and the biosphere. Journal of Environmental Psychology, 21, 327-339.

Spellerberg, Ian. et al.(2012) "Berkshire Encyclopedia of Sustainbility": Measurements, Indicators, and Research Methods for Sustainability. Bekshire Publishing,6.

Stern PC. 2000 “Toward a Coherent Theory of Environmentally Significant Behavior”. Journal of Social Issues, 56, 407-424.

Yu, Tai-Yi \& Tai-Kuei Yu. (2017). “The Moderating Effects of Students' Personality Traits on Pro-Environmental Behavioral Intentions in Response to Climate Change". International Journal of Environmental Research and Public Health. 